\title{
Spatial-Temporal Variation of Population Aging: A Case Study of China's Liaoning Province
}

\author{
Dunyi Guan, ${ }^{1}$ Lei Lei $\mathbb{D}^{1}{ }^{1}$ and Zenglin Han ${ }^{2}{ }^{2}$ \\ ${ }^{1}$ School of Geography, Liaoning Normal University, Dalian, China \\ ${ }^{2}$ Marine Economics and Sustainable Development Research Center, Liaoning Normal University, Dalian, China
}

Correspondence should be addressed to Lei Lei; leileixx@hotmail.com and Zenglin Han; hzl@lnnu.edu.cn

Received 18 April 2020; Accepted 6 June 2020; Published 20 August 2020

Guest Editor: Jianhong (Cecilia) Xia

Copyright (c) 2020 Dunyi Guan et al. This is an open access article distributed under the Creative Commons Attribution License, which permits unrestricted use, distribution, and reproduction in any medium, provided the original work is properly cited.

With the rapid increase of the aging population in China, research on the aging phenomenon has become critical. Studying population aging from a spatial perspective is of vital practical significance. Based on China's census data from 1990 to 2010, this study establishes the indicator system of aging level and chooses the entropy method, standard deviational ellipse, and spatial autocorrelation as main methods. Taking Liaoning province of China as an example, the study measures the aging level of its 100 districts and counties, analyzing the overall spatial movement degree, and elucidates the temporal-spatial evolution of aging development. It further discusses the spatial correlational characteristics between each county unit. The results reveal that, first, the spatial distribution of aging in Liaoning shows an unceasingly intensifying northeast-southwest pattern. County areas along the Shenyang-Dalian line show a stronger effect of aging of the whole province. Second, the average score of aging in all county areas is on the increase; the degree of aging shows an increasing trend, but the speed of aging tends to slow down. Population aging in Liaoning shows an obvious spatial heterogeneity, which is mainly manifested by regional differences, urban-rural differences, and minority differences. Third, Moran's I index of aging level first increases and then decreases; the values are all positive. The overall spatial pattern has a positive correlation; the spatial agglomeration effect is first enhanced and then weakened. The hot spots are distributed in the surrounding counties of Shenyang and Dalian, showing a distribution pattern of two cores; the cold spots gradually form a binary structure represented by Chaoyang-Huludao and Yingkou-Panjin. The study showed the positive spatial correlation of the aging level between the county units, thereby paving the way for future research on the balanced distribution. Population aging studies will contribute to optimize the population structure and promote a virtuous circle of economy. The study showed the positive spatial correlation of the aging level between the county units, thereby paving the way for future research on the balanced distribution. Population aging studies will contribute to optimize the population structure and promote a virtuous circle of economy.

\section{Introduction}

In today's world of a rapidly aging population, aging issues are given close attention and importance. The "silent revolution" caused by declining birthrate and increasing lifespans has taken place all over the world [1]. Compared with developed countries, the aging problem in developing countries usually appears at the lower economic level, and people are more likely unprepared for its rapid and large-scale development. Having both the largest population and the largest aging population, China is one of the fastest growing countries in terms of aging. To encourage births in an aging China, the universal two-child policy was officially implemented in 2015, which means that the family planning policy then ceased to exist. However, far fewer couples than expected have applied to have a second child, and the nationwide fertility rate has been declining by the year. According to the Green Book of Population and Labor reported by China on January 3, 2019, the Chinese population is forecast to see a negative growth and undergo more rapid aging from 2030. In 1996, Liaoning province entered the aging society three years ahead of the national average level, and its development speed was faster than that of the whole country. At present, its fertility rate is the lowest in China; moreover, the "empty nest" syndrome has become common, with the elderly left behind in some areas, among which the disabled elderly and the semi-disabled elderly are not a few. At present, 
Liaoning is a province hit by the double blow of the declining birthrate and economic depression in China. In response to the aging of the population, in 2018, Liaoning province was the first to propose rewarding families with two children, which triggered widespread public concern. The increasingly severe aging problem affects the healthy development of the province's social economy, people's livelihood, and many other aspects with a series of issues related to old-age support, labor supply, and medical security.

In the past three decades, scholars have studied population aging proceeding from demography, sociology, economics, psychology, and other subjects. At the macrolevel, they have studied the impacts of aging on the economy and society [2, 3]; some scholars have predicted the trend of aging and analyzed relative countermeasures [4-7]. At the microlevel, previous studies have focused on social pension $[8,9]$, psychological demands of the elderly [10-12], and their behavior and activity [13-15]. Recently, housing, old-age support, and medical care issues have also become research focuses [16-18]. Regionality is the most prominent feature of population aging, and thus studies on spatial difference from the perspective of geography have increased, which include interregional difference and intraregional difference. The research on interregional difference is mostly carried out in international, domestic, and typical regions. From the results of the spatial distribution of the elderly population as calculated by the Lorenz curve and the Gini coefficient, the number of old people is inversely proportional to the agglomeration degree of their spatial distribution in Baltimore, Pittsburgh, and Philadelphia [19]. Through identifying the principal retirement regions and analyzing the sources of regional elderly population growth in different countries, the different stages of elderly mobility transition have been determined [20]. Studies have also visualized the differences in the aging stage between urban and rural areas, eastern and western regions in China [21]. To analyze the differences and the characteristics of evolution of the aging region, many scholars have also conducted comparative studies from the provincial scale and from the perspective of urban agglomerations [22-24]. There are also clear contrasts between the aging situation in urban and rural area, which has been proved in different countries over a historical period $[25,26])$. In the study of intraregional difference, it has been shown that the density of the elderly in the inner-city is higher than that in suburban areas and new districts, such as in Toledo, USA [27]. Some scholars have come to the same finding that the elderly population in the United States is concentrated in central urban districts and remote rural areas, thus forming a "retirement center" [28-30]. In recent years, studies on the spatial-temporal evolution of aging at the microspatial scale are on the increase. Some studies have analyzed the spatial and temporal distribution characteristics and development trends of aging at the county scale and on multiple scales [31-33]. Some scholars have even gone deep into the township-street scale to study the spatial differentiation of aging in their respective research areas $[34,35]$. Additionally, one view is that the spatial unevenness of aging is under the effect of both migration and aging in place [36].

Based on the period of China's population census, this study determines 1990 to 2010 as the time scale to discuss the aging problem in Liaoning province after the implementation of family planning at the county level, hoping to enrich aging studies at the small scale from a spatial perspective. The study does not choose the regular single indicator, which is the percentage of population over the age of 65 , to measure the aging level, but selects five reasonable indicators to establish an indicator system, showing a certain degree of innovation in the selection of indicators. The study measures the aging level with certain novelty value and makes empirical contribution to the implications of the uneven distribution of aging for developing regions.

\section{Materials and Methods}

2.1. Study Area. Liaoning province is located south of the northeastern part of China, bordering the Yellow Sea and Bohai Sea in the south. It is separated from North Korea by a river to the east and faces Japan and Korea across the sea. The terrain of Liaoning is high in the north but low in the south; mountains and hills are, respectively, located in the east and the west. Toward the end of 2017, the resident population was 43.389 million. Liaoning is one of the important old industrial bases in China and has the most comprehensive industries. The provincial capital of Liaoning is Shenyang. Since 2010, there have been some adjustments made in the administrative divisions of some areas in Liaoning province: In 2014, the Dongling District of Shenyang was renamed as Hunnan District. In 2015, approved by the State Council, Pulandian City was transformed into Pulandian District. Similarly, Liaozhong County of Shenyang and Dawa County of Panjin were changed into Liaozhong District and Dawa District in 2016. Since the research period of this study is from 1990 to 2010, the administrative divisions of Liaoning province here are the version of 2010. Table 1 shows the specific administrative divisions of Liaoning province. There are 100 county-level divisions under the jurisdiction of the municipality, which includes 56 municipal districts, 17 county-level cities, and 27 counties ( 8 of which are minority autonomous counties). Figure 1 shows the administrative map of Liaoning province. To facilitate inspection and comparison, the municipal districts have been merged.

\subsection{Indicator and Data}

2.2.1. Indicator Selection. Most scholars usually use a single indicator for the measurement of aging, which is the proportion of the elderly (population over 65 years) to the total population. Recently, there have been calls for the new measures of aging rather than merely focusing on the chronological age because people's life expectancy and actual situation have changed $[37,38]$. To comprehensively reveal the characteristics of population aging in Liaoning province, this study refers to the classification of population age types proposed by the United Nations and selects the four mentioned indicators to reflect the degree of population aging: (a) the proportion of the elderly population over 65, (b) the proportion of child-age population from 0 to 14 , (c) the ratio of the elderly population to the child-age population, and (d) the median age. In the process of China's population aging, the country is also faced with the rising of the elderly support rate [39]. So, as an important 
TABLE 1: Study area (county-level).

\begin{tabular}{|c|c|}
\hline al city & County-level divisions \\
\hline $\begin{array}{l}\text { Shenyang (Vice-provincial } \\
\text { City) }\end{array}$ & $\begin{array}{c}\text { Heping District, Shenhe District, Dadong District, Huanggu District, Tiexi District, Sujiatun District, } \\
\text { Dongling District, Shenbei New District, Yuhong District, Liaozhong County, Xinmin City, Kangping } \\
\text { County, Faku County }\end{array}$ \\
\hline $\begin{array}{l}\text { Dalian (Vice-provincial } \\
\text { City) }\end{array}$ & $\begin{array}{c}\text { Zhongshan District, Xigang District, Shahekou District, Ganjingzi District, Lushunkou District, Jinzhou } \\
\text { District, Changhai County, Wafangdian City, Pulandian City, Zhuanghe City }\end{array}$ \\
\hline Anshan & $\begin{array}{c}\text { Tiedong District, Tiexi District, Lishan District, Qianshan District, Haicheng City, Tai'an County, Xiuyan } \\
\text { Manchu Autonomous County }\end{array}$ \\
\hline Fushun & $\begin{array}{r}\text { Xinfu District, Shuncheng District, Wanghua District, Dongzhou District, Fushu } \\
\text { Autonomous County, Qingyuan Manchu Autonomous Cc }\end{array}$ \\
\hline Benxi & $\begin{array}{c}\text { Pingshan District, Xihu District, Mingshan District, Nanfen District, Benxi Manchu Autonomous County, } \\
\text { Huanren Manchu Autonomous County }\end{array}$ \\
\hline Dandong & $\begin{array}{r}\text { Yuanbao District, Zhenxing District, Zhen'an District, Dong } \\
\text { Autonomous Cou }\end{array}$ \\
\hline & Guta District, Linghe District, Taihe District, L \\
\hline & Zhanqian District, Xishi District, Bayuquan District, Laobian District, Gaizhou City, Dashiqiao City \\
\hline Fuxin & $\begin{array}{c}\text { Haizhou District, Xinqiu District, Taiping District, Qinghemen District, Xihe District, Fuxin Mongol } \\
\text { Autonomous County, Zhangwu County }\end{array}$ \\
\hline Liaoyang & $\begin{array}{c}\text { Baita District, Wensheng District, Hongwei District, Gongchangling District, Taizihe District, Dengta City, } \\
\text { Liaoyang County }\end{array}$ \\
\hline Panjin & Shuangtaizi District, Xinglongtai District, Dan \\
\hline Tieling & $\begin{array}{c}\text { Yinzhou District, Qinghe District, Diaobingshan City, Kaiyuan City, Tieling County, Changtu County, } \\
\text { Xifeng County }\end{array}$ \\
\hline Chao) & $\begin{array}{c}\text { Shuangta District, Longcheng District, Beipiao City, Lingyuan City, Chaoyang County, Jianping County, } \\
\text { Harqin Zuoyi Mongol Autonomous County }\end{array}$ \\
\hline Huludao & Lianshan District, Longgang District, Nanpiao District, Xingcheng City, Suizhong County, Jianchang County \\
\hline
\end{tabular}

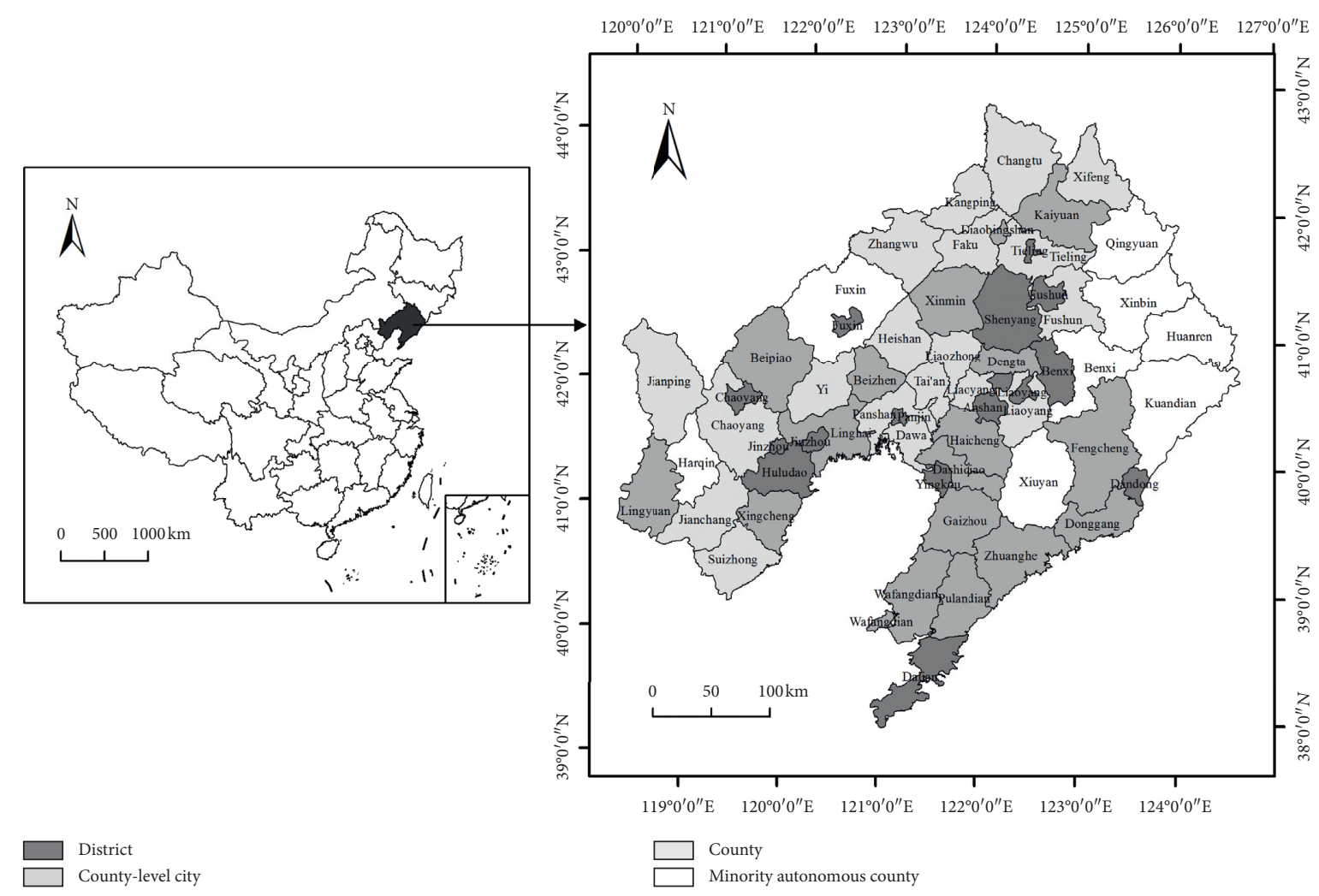

Figure 1: The location of the study area.

socioeconomic indicator to reflect the real-world scenarios, the elderly dependency ratio $(e)$ is also selected to reflect the changes in social support pressures during the aging process.
2.2.2. Data Source. The census provides the main source of the basic population data in China. It provides the population data for all ages, which is indispensable for studying 
aging. China has held three censuses in 1953, 1964, and 1982; 1990 was the fourth census. The first three censuses were carried out irregularly. Since 1990, census has been taken every 10 years periodically, and the recent one is the sixth census. The statistical caliber of this study is the resident population. The data of the 4 th, 5 th, and 6 th census comes from Tabulation on the 1990 Population Census of Liaoning Province (book one), Tabulation of the 2000 Population Census of the People's Republic of China by County, and Tabulation of the 2010 Population Census of the People's Republic of China by County; other social and economic data come from Liaoning Statistical Yearbook and China Statistical Yearbook (county-level) in 1990, 2000, and 2010.

\subsection{Methods}

2.3.1. Entropy Method. There are many methods for multiple indexes comprehensive evaluation and can be summarized into two categories: subjective weighting method and objective weighting method [40]. Among them, the entropy method is relatively objective. Entropy originally came from the thermodynamics concept in physics, which mainly reflects the randomness in the system, and is now widely used in the research fields such as social economy [41, 42]. Using the entropy method to determine the index weights can not only overcome the randomness and assumption that the subjective weighting method cannot avoid, but also effectively solve the problem of overlapping information between multiple index variables. Therefore, the study attempts to use this method to determine the index weight and measure the population aging level. The raw data are processed into the same dimension by min-max normalization, the entropy is defined according to the matrix, and then the weight is confirmed. The processing equation is as follows:

First, define the entropy according to the matrix $X^{\prime}=\left(X_{i j}^{\prime}\right)_{m \times n}\left(0 \leq X_{i j}^{\prime} \leq 1\right)$ :

$$
\begin{aligned}
& E_{j}=-k\left(\sum_{i=1}^{m} p_{i j} \ln p_{i j}\right), \\
& k=\frac{1}{\ln m}, \\
& p_{i j}=\frac{1+X_{i j}^{\prime}}{\sum_{i=1}^{m}\left(1+X_{i j}^{\prime}\right)} \\
& (i=1,2, \ldots ; j=1,2, \ldots, n) .
\end{aligned}
$$

Second, calculate the coefficient of variation of the $j$ th indicator:

$$
F_{j}=1-E_{j}, \quad j=1,2, \ldots, n .
$$

Third, confirm the weights:

$$
W_{j}=\frac{F_{j}}{n_{j=1}^{n} F_{j}} .
$$

Last, calculate the comprehensive score of aging level of the $i$ th county unit $\left(G_{i}\right)$ :

$$
G_{i}=\sum_{j=1}^{m} W_{j} p_{i j}
$$

2.3.2. Standard Deviational Ellipse. Standard deviation ellipse (SDE) is a method widely used in the field of spatial statistics proposed by American sociologist Welty Lefever $[43,44]$. Through the measurement of the center, long axis, short axis, rotation, and other parameters, SDE can quantitatively analyze the overall spatial distribution characteristics of the geographical elements [45-47]. It has been widely used in the spatial distribution pattern of geographic data such as population and residence [7]. This paper uses SDE to reflect the directionality and mobility of the aging level distributed in two-dimensional space to better reveal the spatial and temporal evolution of the aging level in space. The equation is as follows:

mean center: $\overline{X_{w}}=\frac{\sum_{i=1}^{n} W_{i} x_{i}}{\sum_{i=1}^{n} W_{i}} ; \overline{Y_{w}}=\frac{\sum_{i=1}^{n} W_{i} y_{i}}{\sum_{i=1}^{n} W_{i}}$,

standard deviation of short axis $(x): \sigma_{x}$

$$
\frac{\sqrt{\sum_{i=1}^{n}\left(W_{i} \tilde{x}_{i} \cos \theta-W_{i} \tilde{y}_{i} \sin \theta\right)}}{\sum_{i=1}^{n} W_{i}^{2}}
$$

standard deviation of long axis $(y): \sigma_{y}=$

$$
\frac{\sqrt{\sum_{i=1}^{n}\left(W_{i} \tilde{x}_{i} \sin \theta-W_{i} \tilde{y}_{i} \cos \theta\right)}}{\sum_{i=1}^{n} W_{i}^{2}}
$$

where $\left(x_{i}, y_{i}\right)$ is the spatial location of the research object, $W_{i}$ is the weight, $\left(\overline{X_{w}}, \overline{Y_{w}}\right)$ is the weighted mean center, $i$ is the county unit, and $n$ is the number of the counties in Liaoning province. $\theta$ is the rotation of the distribution pattern, and the angle of rotation is calculated as $\tan \theta . \widetilde{x}_{i}$ and $\tilde{y}_{i}$ respectively represent coordinates deviations of study objects from the mean center. $\sigma_{x}$ and $\sigma_{y}$ refer to the standard deviations along the $x$-axis and $y$-axis.

2.3.3. Global Spatial Autocorrelation: Moran's I. To clarify the distribution pattern of the population aging in space, the study uses Exploratory Spatial Data Analysis (ESDA) in GIS to measure the spatial correlation characteristics. Spatial autocorrelation can explain the correlation degree between a certain geographic phenomenon on a unit and the same phenomenon on a neighboring regional unit. It can be divided into global spatial autocorrelation and local spatial autocorrelation [48]. Global Moran's I can measure the overall level of spatial correlation and quantificationally describe the dependence of things and space. It can be used to analyze whether a certain variable has a spatial correlation and the degree of its spatial correlation. Through this method, it can be seen whether the aging level is spatially concentrated, diffused, or evenly distributed from an overall perspective. The equation is as follows: 


$$
I=\frac{n \sum_{i=1}^{n} \sum_{j=1}^{n} W_{i j}\left(x_{i}-\bar{x}\right)\left(x_{j}-\bar{x}\right)}{\sum_{i=1}^{n}\left(x_{i}-\bar{x}\right)^{2}\left(\sum_{i=1}^{n} \sum_{j=1}^{n} W_{i j}\right)},
$$

where $I$ represents the value of Moran's spatial autocorrelation coefficient; $n$ is the number of county units in Liaoning province, $x_{i}$ and $x_{j}$ are the comprehensive scores of aging in the $i$ th and the $j$ th county, $W_{i j}$ is the spatial weight matrix that indicates the proximity relation between $i$ and $j$, and $n$ is the total number of features. Then, conduct the $z$ test: $Z(I)=((I-E(I)) / \sqrt{\operatorname{Var}(I)}), E(I)$ is the mathematical expected value, and $\operatorname{Var}(I)$ is the variance of $I$.

2.3.4. Local Spatial Autocorrelation: Getis-Ord $G_{i}^{*}$. Global Moran's I index is an overall average statistical indicator. Generally, the overall spatial variation and the local spatial variation are not completely consistent. So, the global Moran's I alone is not sufficient to fully reflect the internal characteristics of the spatial differences of the research units [49]. Getis-Ord $G_{i}^{*}$ is one of the local spatial autocorrelation methods; it can identify the high or low values cluster (hot spot and cold spot) of each unit inside the region $[50,51]$. To further study the spatial heterogeneity of aging in Liaoning province and its spatial agglomeration characteristics, the study attempts to use this method to analyze the spatial autocorrelation characteristics of population aging specifically. The equation is as follows:

$$
G=\frac{\sum_{i=1}^{n} \sum_{j=1}^{n} W_{i j} x_{i} x_{j}}{\sum_{i=1}^{n} \sum_{j=1}^{n} x_{i} x_{j}}, \quad j \neq i,
$$

where the $G$ statistic represents the value of Getis-Ord $G_{i}^{*}$, and $x_{i}$ and $x_{j}$ are the comprehensive scores of aging in the $i$ th and the $j$ th county. $W_{i j}$ is the spatial weight between $i$ and $j$. $N$ is the total number of counties. For the convenience of comparison and analysis, standardizing the $G$ statistic, $Z(G)=((G-E(G)) / \sqrt{\operatorname{Var}(G)}), E(G)$ is the mathematical expected value of $G$, and $\operatorname{Var}(G)$ is the variance of $G$.

\section{Results}

3.1. Directional Distribution of Population Aging at the County Scale. According to the calculation results of the comprehensive score of aging level (seen Supplementary materials (available here)), using the geographic distribution tool of ArcGIS, the standard deviational ellipse parameters of population aging in Liaoning province measured from 1990 to 2010 are as shown in Table 2. Figure 2 shows the spatial distribution situation. Overall, the dynamic evolution characteristics of population aging showed a northeastsouthwest pattern in space, which finally moved northwest. The areas distributed inside the ellipse were mainly the districts and counties along the Shenyang-Dalian line of the central-southern part of Liaoning province.

3.1.1. Mean Center Variation. The variation trend of the mean center in SDE could reflect the shift of gravity center on the spatial distribution of aging. As shown in Figure 2,
TABLE 2: SDE parameters variation of population aging in 1990, 2000 , and 2010.

\begin{tabular}{cccccc}
\hline Year & $\begin{array}{c}\text { Long axis } \\
(x)\end{array}$ & $\begin{array}{c}\text { Short axis } \\
(y)\end{array}$ & Rotation & Area & $\begin{array}{c}\text { Axial } \\
\text { ratio }\end{array}$ \\
\hline 1990 & 125.077 & 173.780 & 42.225 & $6.828 \times 104$ & 0.720 \\
2000 & 126.849 & 169.813 & 49.189 & $6.767 \times 104$ & 0.747 \\
2010 & 127.910 & 168.008 & 53.137 & $6.751 \times 104$ & 0.761 \\
\hline
\end{tabular}

the gravity center of aging was generally distributed from south to north (by east). In 1990, the gravity center was in Haicheng city, Anshan. In 2000 and 2010, it remained in Liaoyang county of Liaoyang without cross-regional fluctuation. The direction of the gravity center then shifted to the northeast from 1990 to 2000 and to the northwest from 2000 to 2010. The displacement of the gravity center in the first ten years was obviously longer than that in the last ten years, and the north-south moving distance was greater than the east-west moving distance, which showed the tendency of moving northwards and eastwards. Therefore, the counties in the northeast of the elliptical axis grew faster in terms of population aging than those in the southwest of the axis, which meant that they had a greater impact on the overall development of aging in the province.

3.1.2. Rotation Variation. The rotation in SDE is the angle of the north direction clockwise to the long axis of the ellipse, which can reflect the main directional trend of each element spatially. The variation range of rotation was from $42.225^{\circ}$ to $53.137^{\circ}$, and the angle gradually increased during the period from 1990 to 2010 (see Table 2), indicating that the northeast-southwest pattern of population aging in the province was continuously strengthened. Compared with 2000 , the increase in rotation was relatively small, so that the spatial distribution pattern of aging tended to be stable.

3.1.3. Elliptical Shape Variation. From 1990 to 2010, the area of the ellipse decreased continuously, indicating that the spatial distribution of the aging level was gradually shrinking. The aging level of the areas inside the ellipse grew relatively fast and had a stronger effect on the overall level of population aging in Liaoning province. The growth rate of the aging level in the districts and counties outside the ellipse was slow; so, the degree of aging was relatively moderate. The area of ellipse decreased slightly in the last ten years of the study period, and the spatial spillover effect of the aging level was relatively weak. The long axis of the standard deviation ellipse showed a downward trend, indicating that the aging level was contracting in the north-south direction. The short axis was on the rise, so the aging level was expanding in the east-west direction. The axial ratio increased because the long axis was shortened and the short axis was lengthened. It further illustrated that population aging of each district and county was increasing in the east-west direction obviously, showing an expanding trend. 


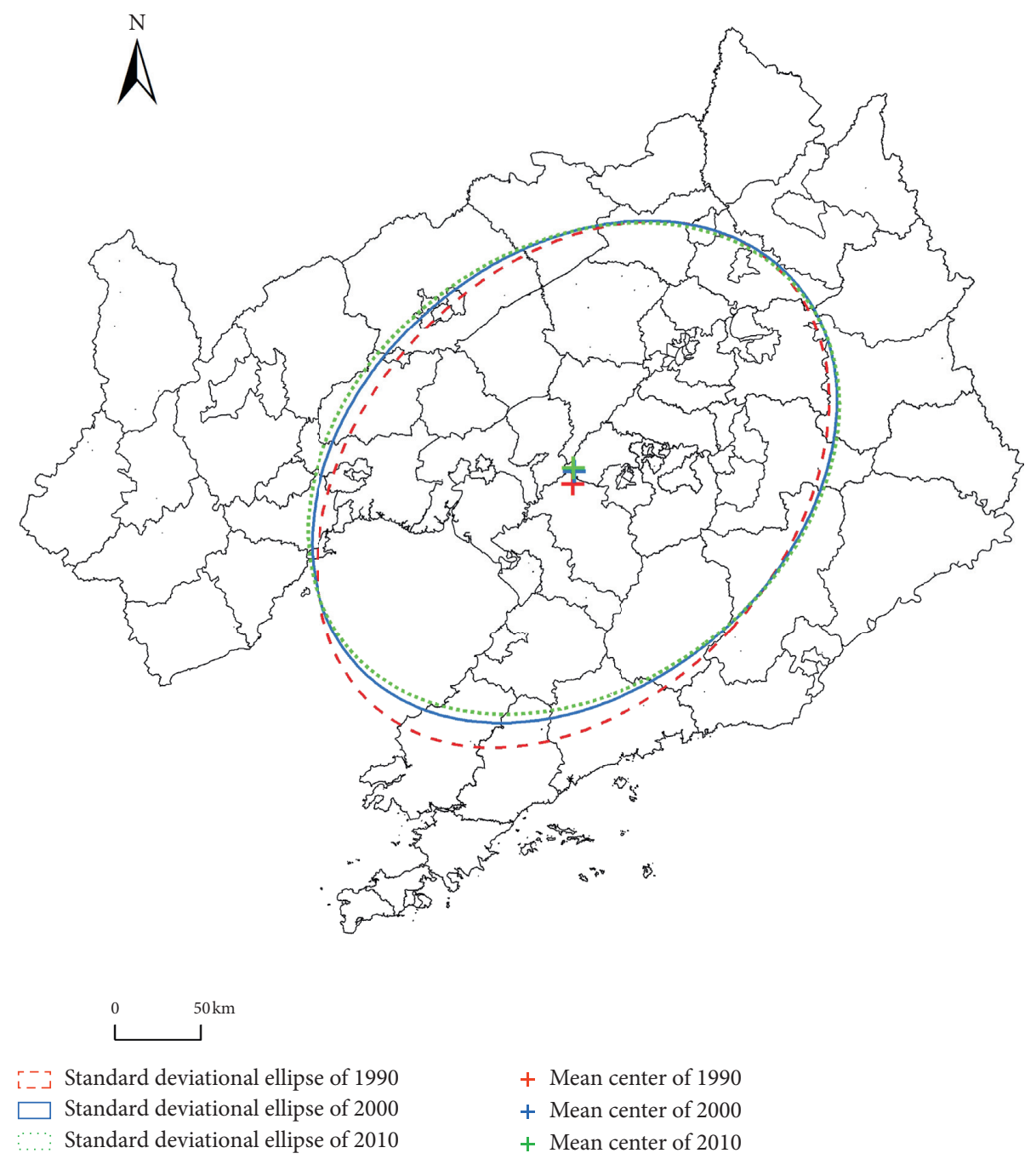

Figure 2: Standard deviational ellipse of population aging from 1990 to 2010.

\subsection{Spatial-Temporal Evolution of Population Aging at the County Scale}

3.2.1. Temporal Variation Analysis. According to the calculation results of the comprehensive score of aging level in Liaoning province at the county scale (seen Supplementary materials), as to the development level, the average scores of population aging in 1990, 2000, and 2010 were $0.193,0.339$, and 0.690 , respectively, indicating that aging in Liaoning province was constantly becoming more severe from 1990 to 2010 . As to the growth rate, the average growth rate of aging from 1990 to 2000 was $105 \%$, which was significantly greater than the average growth rate from 2000 to 2010 (77\%). Although the growth rate of aging was relatively stable during the study period, it does not mean that the development speed of population aging will continue to slow down. There were two nationwide baby booms in the history of China, which were from 1950 to 1957 and from 1962 to 1971, respectively. Due to the influence of the "population momentum," the emergence of a birth boom will bring about a peak in population aging after about 60 years. When those baby boomers reach the advanced age, they will live under the pressure of public service management, which brings great influence on their living conditions [52]. As to the horizontal differentiation, the coefficient of variation for the three years was $0.295,0.203$, and 0.163 , respectively, indicating that the difference in aging level was decreasing.

3.2.2. Regional Difference Analysis. To further analyze the spatial difference of aging and based on the principle of Nelson's classification, the study divided population aging in Liaoning province into six levels and rounded the break values to the nearest one decimal place: $X<0.2$ (the lowest level), $0.2<X<0.3$ (low level), $0.3<X<0.4$ (lower intermediate level), $0.4<X<0.6$ (intermediate level), $0.6<X<0.7$ (higher intermediate level), and $X>0.7$ (high level). As shown in Figure 3, in 1990, the comprehensive level of aging in the province was below the lower intermediate level. The areas at the lower intermediate level were mainly concentrated in the central-southern part of Liaoning, sporadically distributed in the urban districts in Shenyang and Dalian, Fushun county in Fushun, and Yuanbao district in Dandong. Nearly $31 \%$ of the county regions were at the lowest 


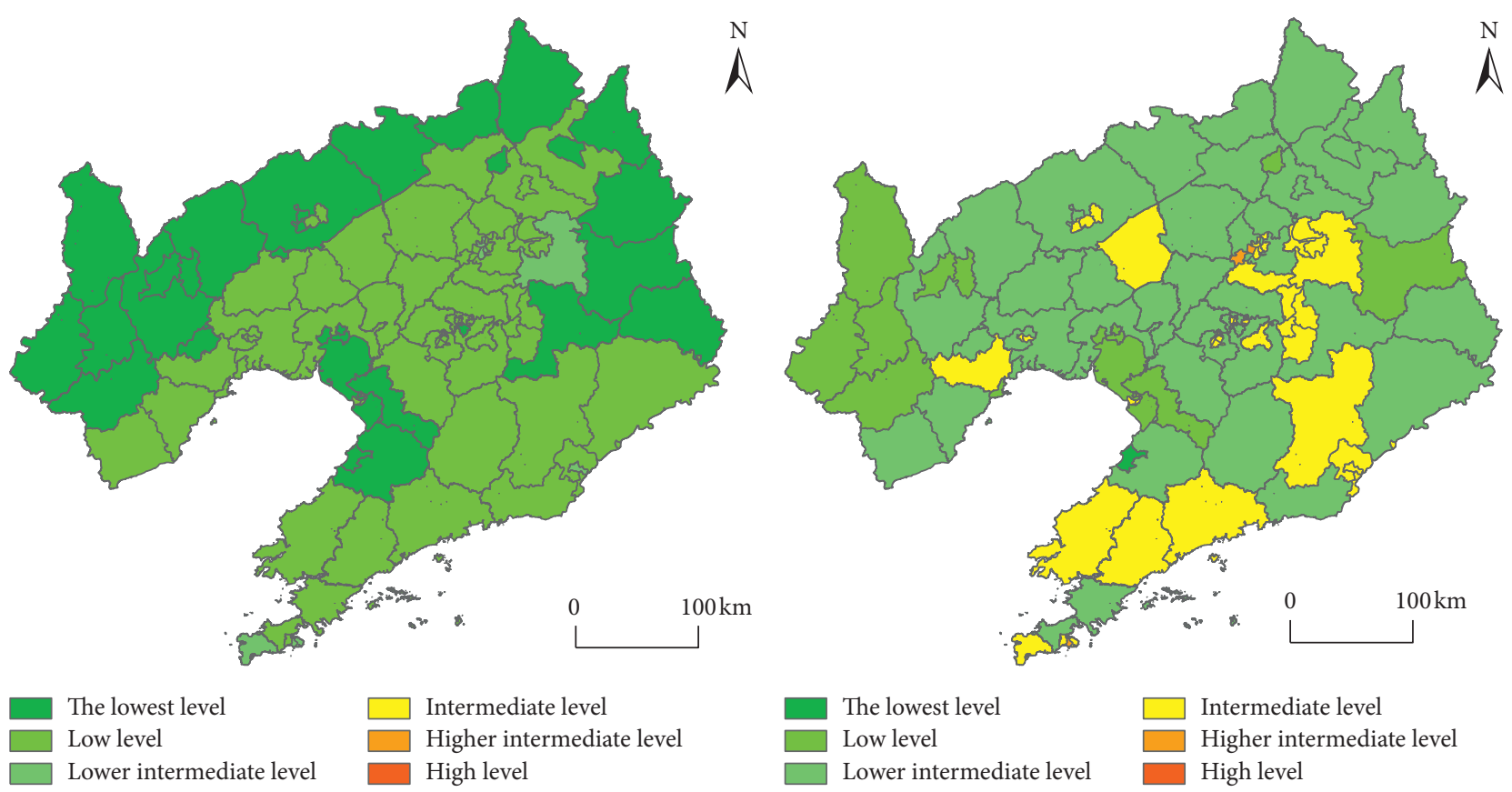

(a)

(b)

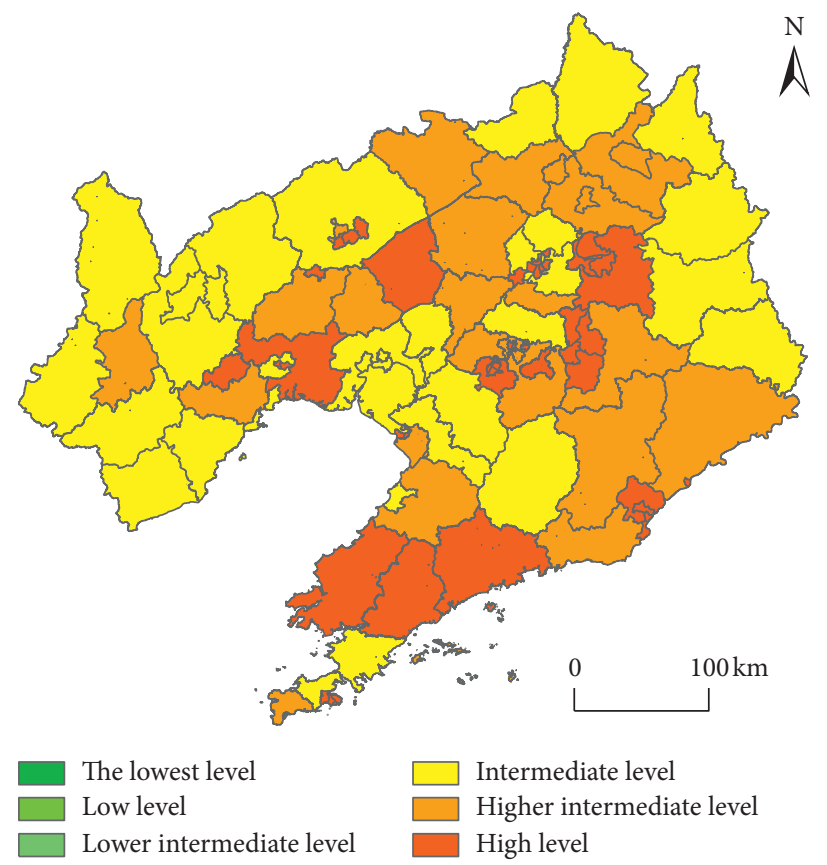

(c)

Figure 3: Score grades of population aging level in Liaoning county regions in (a) 1990, (b) 2000, and (c) 2010.

level, mainly distributed in western and northern Liaoning. Low-level areas were in large quantity and distributed widely, accounting for $61 \%$ of all districts and counties. In 2000, except for Bayuquan district in Yingkou, the rest of the areas had been out of the lowest level. The distribution range of areas at the higher intermediate level was small; the main urban districts of Shenyang and Dalian formed the doublecore structure. Intermediate level areas accounted for 39\% of all counties and displayed an areal distribution pattern scattered in the urban area. The number of areas at the lower intermediate level was relatively large, accounting for $44 \%$ of all the districts and counties, and formed a continuous areal distribution pattern. Almost 14\% of the districts and counties were at the low level, mainly distributed in the western and northern rural counties of Liaoning; the individual districts and counties of Yingkou and Panjin were also at this level. By 2010, the province was all above the intermediate level. High-level counties were in the majority, which were concentrated in the urban areas of 10 cities, accounting for $41 \%$ of all counties. Almost $32 \%$ of the 
districts and counties were at the intermediate level, mainly distributed in the inland county regions of the western and northern part of Liaoning, as well as the county-level units belonging to the urban agglomeration of central Liaoning. A total of $26 \%$ of the counties were at the higher intermediate level. The overall degree of population aging was generally high in 2010. In the early period of the founding of People's Republic of China, Liaoning province recruited workers from all over the country. As one of the most important heavy industrial bases in China, the central-southern Liaoning industrial base was composed of Shenyang and its surrounding areas, Dalian and other coastal cities, attracting a large number of young adults to flock here to participate in construction. By the 1990s, this kind of population was gradually getting old, which aggravated the aging degree in the central-southern of Liaoning province. As the main force of economic growth in Liaoning, the infrastructures in Shenyang and Dalian were relatively better than those in other regions, and hence, its aging level was higher.

\subsubsection{Urban-Rural Difference and Minority Difference} Analysis. Through the calculation on raw data, the scores of population aging in the urban areas and rural areas as well as the minority counties and nonminority counties were obtained. As shown in Figure 3, there were obvious urban-rural differences and minority difference in population aging in Liaoning county regions. In 1990, 2000, and 2010, the ratio of the overall aging level at urban areas to rural areas increased first and then decreased, which was 1.172, 1.284, and 1.207 , respectively. The overall urban-rural difference was getting much larger and showed fluctuation at different times. The aging levels of most urban areas were higher than those of rural areas. However, the urban-rural ratios of aging were less than 1 in the mountainous areas of western and northern Liaoning, as well as several coastal cities, which illustrated that the degree of population aging in rural areas was higher than that in urban areas of these places. The family planning policy was strictly implemented in the cities at the beginning, and then deep in the countryside. In 1984, China began to allow rural families with only daughter to have a second child, which reduced the population aging in rural areas. On the contrary, the relatively developed urban areas with more job opportunities began to have a siphoning effect on the young labor-force in rural areas. The young adults rushed to nearby small-middle cities and then flooded into the main cities of the Shenyang Economic Zone and the Liaoning Coastal Economic Belt with the residents of smallmiddle cities and no longer come back to farming in their home village. Especially in the remote and poor rural counties, the reduction of the working-age population aggravated the aging process of the out-migration areas.

During the study period, the average population aging scores of the minority autonomous counties were 0.138 , 0.320 , and 0.614 , which was lower than those of nonminority areas $(0.198,0.400$, and 0.696$)$, and to some extent brought down the overall level of the province $(0.193,0.393$, and 0.690). In addition, the aging levels of the eight minority autonomous counties were all lower than those of the nonminority districts and the entire province. This result was because the minority areas were seriously affected by traditional fertility concepts; additionally, the family planning policy in these areas was relatively loose because of the special care from the country. According the policy, if both parents were minority, they were allowed to have a second child. So, the higher fertility rate greatly delayed the local aging process and increased the minority differences.

\subsection{Spatial Correlation Characteristics of Population Aging at the County Scale}

3.3.1. Global Spatial Correlation Characteristics Analysis. With the analyzing patterns tool of ArcGIS, the global Moran's I index and correlation values were found as shown in Table 3. The value of Moran's I index was between -1 and 1 ; $z$-score was positive and greater than 1.96; $p$ value was less than 0.05 , indicating that the test passed the significance level, and the confidence was high. Under the confidence level of 0.05 , there was a positive correlation between aging of the county units in Liaoning province from 1990 to 2010 because Moran's I indexes were greater than 0 , which meant that the high level areas were surrounded by the areas also with high aging level and vice versa. The $z$-scores were all greater than 1.96 and showed an obvious spatial agglomerating characteristic. Moran's I index increased from 1990 to 2000 , but the increase rate was not large, indicating that the spatial agglomeration degree of aging in Liaoning province was slightly enhanced because it was relatively stable. From 2000 to 2010, the correlation coefficient decreased and spatial agglomeration degree weakened. The spatial distribution of population aging in each district and county began to gradually develop toward a balanced distribution model.

\subsubsection{Local Spatial Correlation Characteristics Analysis.} Calculated using the hot spot analysis tool of ArcGIS, the Getis-Ord $G_{i}^{*}$ indexes of population aging scores were divided into hot spot, secondary hot spot, secondary cold spot, and cold spot in accordance with the order from high to low by using Jenks natural breaks (Figure 4). The aging of Liaoning province from 1990 to 2010 shows obvious spatial evolution characteristics with some traces in the evolution process.

In 1990, the cold and hot spots in the aging population of Liaoning province were characterized by punctate distribution. The hot spot in central Liaoning was in Xinmin city, Liaozhong county, and the urban districts of Shenyang, as well as Fushun, most county units in Liaoyang, and the Xihu district in Benxi; the hot spot in southern Liaoning was in the main urban areas and Lushunkou District in Dalian. The cold spot was mainly distributed in Chaoyang of western Liaoning and individual districts and counties of Yingkou. The secondary cold spot was surrounded by the periphery of the cold spot, which was composed of Chaoyang, Jianchang county in Huludao, Laobian district and Bayuquan district in Yingkou, and Dawa county in Panjin. Compared with 1990, the spatial pattern of population aging in 2000 changed 
TABLE 3: Moran's I estimators for the score of population aging level in Liaoning county regions in 1990, 2000 , and 2010.

\begin{tabular}{lcccc}
\hline Year & Moran's I index & $E(I)$ & $z$-score & $p$ value \\
\hline 1990 & 0.46 & -0.01 & 5.07 & 0.0000 \\
2000 & 0.48 & -0.01 & 5.24 & 0.0000 \\
2010 & 0.26 & -0.01 & 2.98 & 0.0029 \\
\hline
\end{tabular}

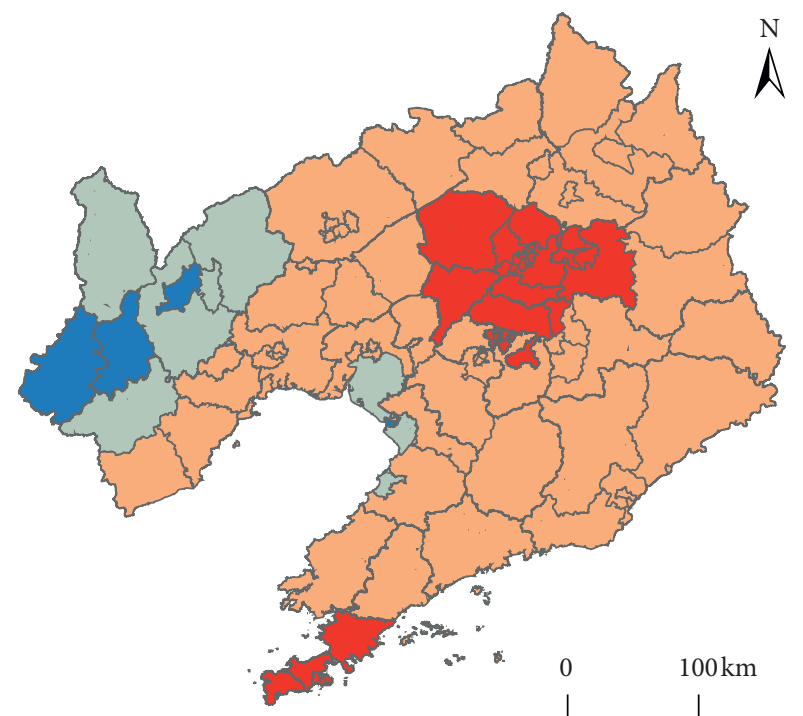

Cold spot

Secondary cold spot
Secondary hot spot

Hot spot

(a)

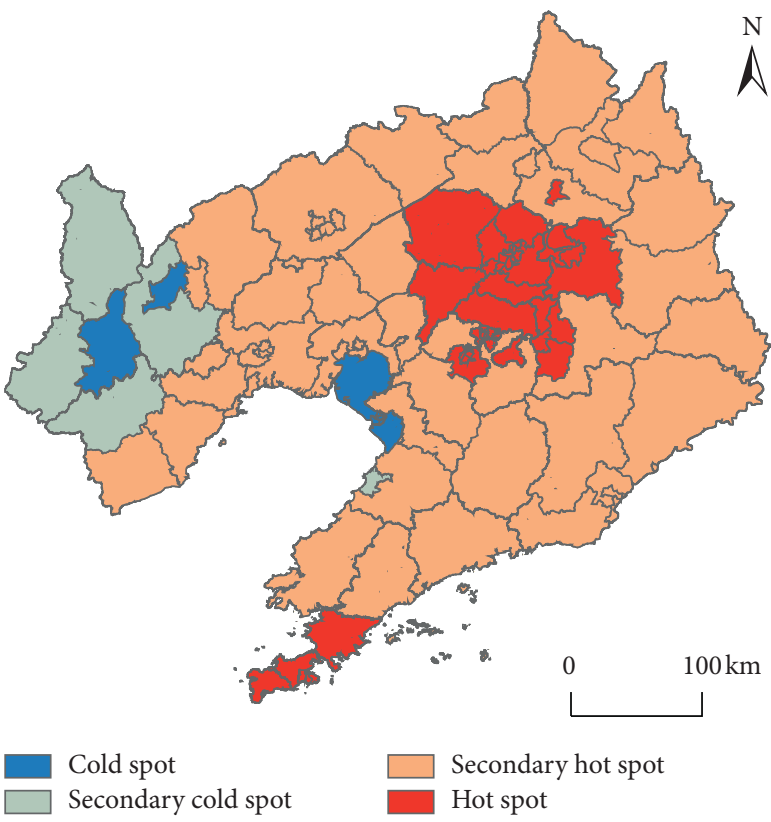

(b)

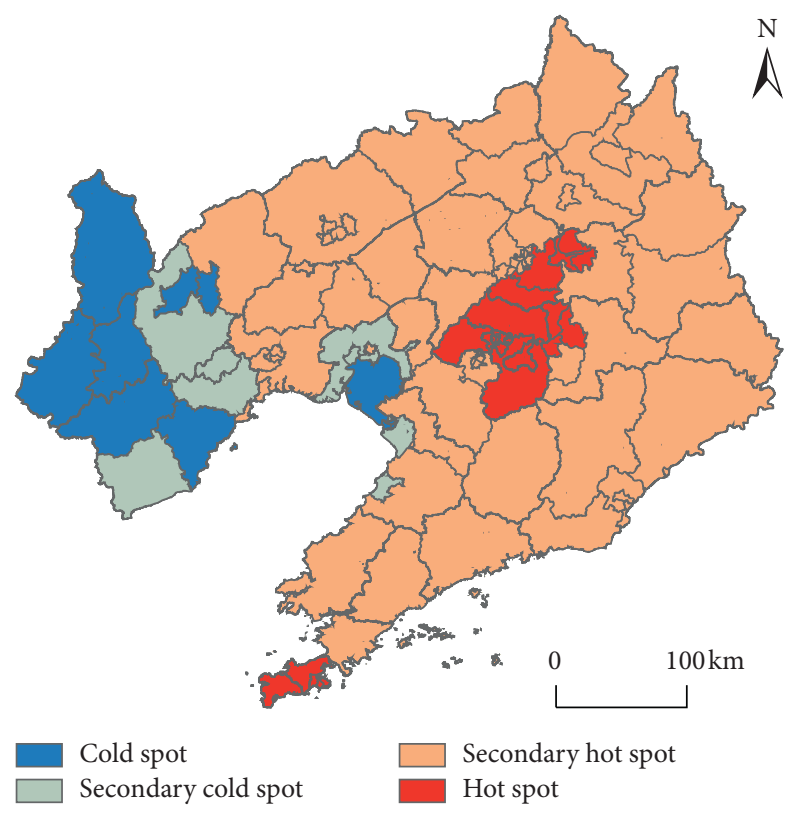

(c)

FIGURE 4: Local spatial correlation of population aging in Liaoning county regions in (a) 1990, (b) 2000, and (c) 2010.

a little and was of relative stability. It expanded to the main urban areas of Liaoyang, Anshan and Benxi. At the same time, the urban districts of Tieling were the newly added hot spot areas, which were to the north of the former hot spot.
The former cold spot of several counties around Yingkou moved northward and expanded to all the main urban areas of Yingkou. Dawa county changed from former secondary hot spot to cold spot. The number of secondary cold spot 
areas in Chaoyang reduced to two. In 2010, the hot spot showed a shrinking situation. The remaining Sujiatun district and Dongling district in Shenyang stayed in the hot spot. The hot spot areas in Fushun and Benxi were degraded to their main urban areas. The urban districts of Anshan and Tieling changed from hot spot to secondary hot spot; Liaoyang county of Liaoyang became the newly added hot spot area. On the contrary, the cold spot expanded within the respective administrative jurisdictions. Jianchang county and Yuzhong county of Huludao changed from secondary cold spot to cold spot.

The range of the hot spot was not large in 1990, 2000, and 2010. The hot spot centered on Shenyang and Fushun slightly expanded to the peripheral area from 1990 to 2000 and shrunk spatially from 2000 to 2010 . The change in the overall range of the hot spot indicated that the high-value spatial agglomeration of aging in Liaoning province was first strengthened and then weakened. The range of the cold spot was relatively small, but it showed a tendency to continuous expansion. From 1990 to 2000, the cold spot of the surrounding counties in Yingkou moved northward to a small extent, indicating that the low-value spatial agglomeration in this area was enhanced. By 2010, the expansion of the cold spot in the western Liaoning was obviously showing that its low value agglomeration effect was enhanced. Most of the county units in Liaoning province were encompassed by the secondary hot spot, which dominated the spatial pattern. The secondary cold spot was mainly distributed around the cold spot, and its range was gradually reduced.

\section{Conclusion}

The comprehensive index of aging in this study can measure the aging condition of a certain area from three aspects, which are quantity, age structure, and pressure of old-age caring. This paper first grasps the main distribution direction of aging in Liaoning province and further discusses the dynamic evolution of the aging distribution between individual counties, urban areas and rural areas, and minority areas and nonminority counties and finally gains valuable insight into the overall and internal spatial correlations of aging.

The study can be summarized by saying that the aging of Liaoning province was generally a northeast-southwest trend in space and that this pattern was continuously strengthened. The displacement of the center of gravity was not large, showing a north-eastern trend. There was a spatial contraction in the distribution of population aging, and the growth rate of aging in the central-southern of Liaoning province was relatively fast, which drove the overall development of aging in the province. The directionality of the aging distribution became increasingly obvious, and expansion was in the east-west direction. In the last ten years of the study period, the distribution pattern of aging tended to be stable.

The degree of aging in Liaoning province gradually increased and its speed stabilized. The spatial difference in intensity showed a weakening trend; high aging level areas were concentrated on the central-southern of Liaoning, followed by the coastal areas of eastern and western Liaoning. The aging level in the mountainous areas of western and northern Liaoning was the lowest. The developmental level of aging in urban areas was generally higher than that of rural areas, but this situation was reversed in some areas. Besides, the pressure of population aging in minority autonomous counties was relatively small.

The positive spatial correlation of the aging level between the county units was obvious, and the spatial agglomeration effect was first enhanced and then weakened. Shenyang and Dalian were the key areas for population aging; the western Liaoning was the low value area for aging. During the study period, there were neither high-value clusters nor low value clusters with a very broad range of influence. The radiation effect on the surrounding districts and counties was limited, and the population aging in most areas was in a state of balanced distribution at a relatively high level.

The entire Northeast of China has already sounded the population alarm. How to solve the problem of aging has been put on the agenda. Scientifically analyzing and understanding the phenomenon of population aging is the key to actively coping with this problem and is vital to the future sustainable development of various fields in the province. Taking Liaoning province as an example, this study enriches the understanding of the internal differences in aging from a spatial perspective, which can be of reference for the formulation of corresponding population policies.

\section{Discussion}

The spatial variation characteristics of aging in Liaoning province are basically consistent with the differences in social and economic development. The overall level of aging in urban areas along the Shenyang-Dalian line and nonminority areas is higher. The main reason for such differentiation is the imbalance of economic and cultural development. Under the historical background of the construction of the Liaoning Central-South Industrial Base, the economic development of industrial cities and port cities starts faster relying on the superior geographical location, national policy support, and natural resource advantages. The local financial revenue in these areas is more secure; thus the level of medical services and cultural education is relatively high. According to the Provincial Working Committee Office on Aging, population aging in Liaoning is also related to the highly developed health system and prolonged rise in longevity. Due to the high level of urbanization and cultural education, the traditional concepts of fertility such as "preference for a son," "more children bring more happiness," and "carrying on the family line" are fading faster in these developed areas. Many studies indicate that the declining trends of birthrate and mortality have led to the acceleration in the population aging in China [10,53]. This opinion is in accordance with the changes in the model of population reproduction, which is mentioned in the demographic transition theory. The implementation of the family planning policy in rural areas and minority areas is relatively moderate. Policy factor has affected birth rates and is also the reason for the lower pressure of aging in these 
areas. However, the phenomenon of "urban-rural inversion" of aging level exists in the less developed areas such as mountain areas and rural area. The aging gap between urban areas and rural areas in Liaoning is growing from 1990 to 2010. As population mobility continues to increase, the working-age population is declining in less developed areas and tends to migrated to developed urban areas, then many elderly population are left behind in rural areas, which is why people are more aged and aging more rapidly in these areas $[25,54,55]$. The spatial variation of aging is expanding, and the weakening of spatial agglomeration partly reflects the trend of urban-rural inversion of aging in Liaoning province.

China has recently proposed the policy of delaying retirement. Population aging itself is neither good nor bad, and old people are not useless and incapable. According to the concept of "productive aging," the whole society should think of the ability, experience, and superior knowledge of the elderly as a resource rather than see the elderly as a burden while restraining aging [56]. The many state-owned enterprises in Liaoning province are also responsible for the large number of retirees. The cost of social medical care and endowment insurance is the financial burden of the government, which has a certain negative impact on the economy. This is consistent with a preceding study [57]. However, aged residents in Liaoning province have higher pensions and savings, which means that they have the potential ability for consumption. Some scholars have also suggested that the deeper the aging, the greater the demand of products for the elderly, which can stimulate the development of the aging industry [2]. Consequently, encouraging social capital to invest in the aging industry can not only keep the elderly healthy but also promote social and economic development.

As to the province to most effectively implement the family planning policy, the first generation of single-child parents in Liaoning has entered old age, and the increase in the number of elderly parents whose only child passed away has become a serious social problem. To adult children, the lack of siblings means that they have heavy burden to support their older parents [58]. In addition, the population in Liaoning province is still one where "women outnumber men" and "get old before getting rich." Confronted with the present situation of economic depression and brain drain, whether Liaoning's current pronatalist policy can alleviate the deepening aging problem is still unknown. The county units and minority communities with a small population base and insufficient public resources have a relatively poor ability to cope with aging, which is the focus of the aging work in the province.

Population aging in Liaoning province is not only representative of the trend in China, but also a typical example with distinctive regional characteristics. There is a practical significance in choosing Liaoning province as the starting point of this study. The study measures the aging level with certain novelty value by establishing the indicator system and makes empirical contribution to the implications of the uneven distribution of aging for developing regions. The sample size of this paper is adequate, and the results obtained by ESDA are accurate enough. Through further analysis, the conclusion is true and effective with a certain rationality and reliability. Due to the limitations of social and economic data at the county scale, the quantitative analysis of the formation mechanism of aging in Liaoning province needs to be further discussed. In 2020, China will carry out the seventh census, which is a future research direction to explore the issue of population aging with more timeliness.

\section{Data Availability}

Some or all data and models generated or used during the study are available online in accordance with finder data retention policies and are available from the authors upon request.

\section{Disclosure}

The funders had no role in the design of the study; in the collection, analyzes, or interpretation of data; in the writing of the manuscript; or in the decision to publish the results.

\section{Conflicts of Interest}

The authors declare that they have no conflicts of interest.

\section{Acknowledgments}

The authors gratefully acknowledge Xinxin Qu for providing the census data of Liaoning in 1990. Thanks are also due to Dr. Ying $\mathrm{Hu}$ and Dr. Yingying Yuan of our laboratory at Marine Economics and Sustainable Development Research Center for their valuable discussion. This work was supported by the Major Program of Humanities \& Social Sciences Key Research Institute of the Ministry of Education of China (grant number 18JJD790005) and the General Program of the National Natural Science Foundation of China (grant number 41571122).

\section{Supplementary Materials}

Comprehensive score of aging level in 1990, 2000, and 2010. (Supplementary Materials)

\section{References}

[1] D. T. Rowland, "Population aging: the transformation of societies," Journal of Women \& Aging, vol. 28, no. 4, pp. 346-347, 2012.

[2] R. Zhang, J. Kreps, and J. Spengler, "Economics of aging: a survey," Journal of Economic Literature, vol. 16, no. 3, pp. 919-962, 1978.

[3] T.-j. Kim and G. J. D. Hewings, "Endogenous growth in an aging economy: Evidence and policy measures," The Annals of Regional Science, vol. 50, no. 3, pp. 705-730, 2013.

[4] J. Bijak, D. Kupiszewska, and M. Kupiszewski, "Replacement migration revisited: simulations of the effects of selected population and labor market strategies for the aging Europe, 2002-2052," Population Research and Policy Review, vol. 27, no. 3, pp. 321-342, 2008.

[5] B. Edmonston, "Population dynamics in Germany: the role of immigration and population momentum," Population Research and Policy Review, vol. 25, no. 5-6, pp. 513-545, 2007. 
[6] R. Lee and A. Mason, "Some macroeconomic aspects of global population aging," Demography, vol. 47, no. 1, pp. S151-S172, 2010.

[7] J. M. Li, "Space-time variation of Chinese aging based on bayesian hierarchy spatio-temporal model," Statistical Research, vol. 33, no. 8, pp. 89-94, 2016.

[8] D. G. Blazer, "Social support and mortality in an elderly community population," American Journal of Epidemiology, vol. 115, no. 5, pp. 684-694, 1982.

[9] N. Krause, "Life stress, social support, and self-esteem in an elderly population," Psychology and Aging, vol. 2, no. 4, pp. 349-356, 1987.

[10] N. Valdez-Torres and L. Waite, "Disability, psychological well-being, and social interaction in later life in China," Research on Aging, vol. 41, no. 4, pp. 362-389, 2019.

[11] B. Resnick, N. J. Klinedinst, L. Yerges-Armstrong, E. Y. Choi, and S. G. Dorsey, "The impact of genetics on physical resilience and successful aging," Journal of Aging and Health, vol. 27, no. 6, pp. 1084-1104, 2015.

[12] D. F. Warner and S. A. Adams, "Physical disability and increased loneliness among married older adults," Society and Mental Health, vol. 6, no. 2, pp. 106-128, 2016.

[13] M. W. Horner, M. D. Duncan, B. S. Wood, Y. Valdez-Torres, and C. Stansbury, "Do aging populations have differential accessibility to activities? Analyzing the spatial structure of social, professional, and business opportunities," Travel Behaviour and Society, vol. 2, no. 3, pp. 182-191, 2015.

[14] S. Rosenbloom, "Sustainability and automobility among the elderly: an international assessment," Transportation, vol. 28, no. 4, pp. 375-408, 2001.

[15] T. Schwanen and A. Páez, "The mobility of older people-an introduction," Journal of Transport Geography, vol. 18, no. 5, pp. 591-595, 2010.

[16] S. M. Golant, "The origins, programs, and benefits of agefriendly communities," The Gerontologist, vol. 56, no. 3, pp. 597-598, 2016.

[17] L. S. Yang, H. R. Li, Y. H. Li et al., "Progress of medical geography and Environmental health studies," Progress in Geography, vol. 29, no. 1, pp. 31-44, 2010.

[18] J. Yu, W. R. Mark, and Y. Cheng, "Aging at home and the intent to relocate in Beijing," Progress in Geography, vol. 34, no. 12, pp. 1577-1585, 2015.

[19] A. C. Goodman, "Using Lorenz curves to characterise urban elderly populations," Urban Studies, vol. 24, no. 1, pp. 77-80, 1987.

[20] A. Choi, J. F. Watkins, and J. A. Woodward, "Interregional elderly migration and population redistribution in four industrialized countries. A comparative analysis," Research on Aging, vol. 12, no. 3, pp. 251-293, 1990.

[21] W.-Y. Wang, L. Zhang, H.-R. Li, R.-B. Li, L.-S. Yang, and Y.-F. Liao, "Spatial-temporal changes and trends of ageing in China," Chinese Geographical Science, vol. 15, no. 3, pp. 200-205, 2005.

[22] L. Shan and L. Ding, "Comparative research on the feature of spatial distribution of aging population between China and Japan," Chinese Journal of Population Science, vol. 7, no. 4, pp. 89-96, 2013.

[23] L. C. Wang, R. W. Wu, and W. Li, "Spatial-temporal patterns of population aging on China's urban agglomerations," Acta Geographica Sinica, vol. 72, no. 6, pp. 1001-1016, 2017.

[24] Z. B. Li, T. S. Sun, J. F. Zhang et al., "Regional types' division of population aging and analysis on population aging regional evolution: based on China, America, Japan and R O Korea," Scientia Geographica Sinica, vol. 35, no. 7, pp. 822-830, 2015.
[25] Y. Cheng, S. Gao, S. Li, Y. Zhang, and M. Rosenberg, "Understanding the spatial disparities and vulnerability of population aging in China," Asia \& the Pacific Policy Studies, vol. 6, no. 1, pp. 73-89, 2019.

[26] N. S. Walford and S. Kurek, "A comparative analysis of population ageing in urban and rural areas of England and wales, and Poland over the last three census intervals," Population, Space and Place, vol. 14, no. 5, pp. 365-386, 2008.

[27] B. W. Okunuki and J. Hiltner, "Intraurban location of the elderly," Journal of Gerontology, vol. 30, no. 4, pp. 473-478, 1975.

[28] D. O. Cowgill, "Residential segregation by age in American metropolitan areas," Journal of Gerontology, vol. 33, no. 3, pp. 446-453, 1978.

[29] C. B. Flynn, "General versus aged interstate migration, 1965-1970," Research on Aging, vol. 2, no. 2, pp. 165-176, 1980.

[30] E. Steinfeld and S. M. Golant, "A place to grow old: the meaning of environment in old age," Economic Geography, vol. 61 , no. 4, p. 381, 1985.

[31] J. J. Liu, Z. W. Ding, G. S. Zhang et al., "Multi-scale spatiotemporal pattern of aging population in central plains region," Economic Geography, vol. 36, no. 4, pp. 29-37, 2016.

[32] L. Lin and F. Ma, "Spatial distribution and trends of the aging of population in Guangzhou," Geographical Research, vol. 5, no. 5, pp. 1043-1054, 2007.

[33] K. Z. Zhang and N. Chen, "Characteristics of spatial-temporal evolution in population aging and driving mechanism at county level in Fujian Province during 1990-2010," Progress in Geography, vol. 33, no. 5, pp. 605-615, 2014.

[34] X. Yuan, Y. Zhao, X. L. Zhang et al., "Spatial variation of population aging and associated factors in Jiangsu province," Scientia Geographica Sinica, vol. 37, no. 12, pp. 1859-1866, 2017.

[35] C. S. Zhou, X. M. Tong, J. H. Wang et al., "Spatial differentiation and the formation mechanism of population aging in Guangzhou in 2000-2010," Geographical Research, vol. 37, no. 1, pp. 103-118, 2018.

[36] M. T. Atkins, ““On the move, or staying put?” an analysis of intrametropolitan residential mobility and ageing in place," Population, Space and Place, vol. 24, no. 3, Article ID e2096, 2018.

[37] W. C. Sanderson and S. Scherbov, "The characteristics approach to the measurement of population aging," Population and Development Review, vol. 39, no. 4, pp. 673-685, 2013.

[38] N. Shiode, M. Morita, S. Shiode, and K.-I. Okunuki, "Urban and rural geographies of aging: a local spatial correlation analysis of aging population measures," Urban Geography, vol. 35, no. 4, pp. 608-628, 2014.

[39] J. Woo, T. Kwok, F. K. H. Sze, and H. Y. Yuan, "Ageing in China: health and social consequences and responses," International Journal of Epidemiology, vol. 31, no. 4, pp. 772775, 2002.

[40] D. J. Wang, Q. M. Zhou, Z. Chang et al., "A new multi-index comprehensive evaluation method," Statistics \& Decision, vol. 4, no. 7, pp. 137-138, 2007.

[41] C. L. Fang and Y. D. Wei, "Evaluation on the sustainable development capacity and regularity of its regional differentiation in Hexi region," Acta Geographica Sinica, vol. 5, no. 5, pp. 560-568, 2001.

[42] J. Qiao, "Application of improved entropy method in henan sustainable development evaluation," Resources Science, vol. 26, no. 1, pp. 113-119, 2004. 
[43] D. W. Lefever, "Measuring geographic concentration by means of the standard deviational ellipse," American Journal of Sociology, vol. 32, no. 1, pp. 88-94, 1926.

[44] D. W. S. Wong, "Several fundamentals in implementing spatial statistics in GIS: using centrographic measures as examples," Annals of GIS, vol. 5, no. 2, pp. 163-174, 1999.

[45] L.-N. Tellier, "Projecting the evolution of the north american urban system and laying the foundations of a topodynamic theory of spatial polarization," Environment and Planning A: Economy and Space, vol. 27, no. 7, pp. 1109-1131, 1995.

[46] R. S. Yuill, "The standard deviational ellipse; an updated tool for spatial description," Geografiska Annaler: Series B, Human Geography, vol. 53, no. 1, pp. 28-39, 1971.

[47] H. B. Zhao, D. F. Yu, C. H. Miao et al., "The location distribution characteristics and influencing factors of cultural facilities in Zhengzhou based on POI data," Scientia Geographica Sinica, vol. 38, no. 9, pp. 1525-1534, 2018.

[48] X. Hu, X. L. Tan, H. M. Zhu et al., "Spatial pattern characteristics of rural settlements in changsha city," Areal Research and Development, vol. 34, no. 1, pp. 138-143, 2015.

[49] Y. J. Zhang, L. Q. Ye, Q. J. Shao et al., "Temporal-spatial difference of population aging in China at city-level," Geomatics \& Spatial Information Technology, vol. 38, no. 12, pp. 18-21, 2015.

[50] A. Getis and J. K. Ord, "The analysis of spatial association by use of distance statistics," in Perspectives on Spatial Data Analysis. Advances in Spatial Science (The Regional Science Series), L. Anselin and S. Rey, Eds., Springer, Berlin, Heidelberg, 2010.

[51] J. K. Ord and A. Getis, "Local spatial autocorrelation statistics: distributional issues and an application," Geographical Analysis, vol. 27, no. 4, pp. 286-306, 2010.

[52] S. Pinnegar, R. V. D. Nouwelant, B. Judd et al., Understanding Housing and Location Choices of Retiring Australians in the "Baby Boom" Generation, City Futures Research Centre, UNSW, Sydney, Australia, 2012, http://apo.org.au/node/ 32971.

[53] Y. Lloyd-Sherlock, A. Hicks, and A. E. While, "Loneliness and social support of older people in China: a systematic literature review," Health \& Social Care in the Community, vol. 22, no. 2, pp. 113-123, 2014.

[54] S. Jin, J. Yang, E. Wang, and J. Liu, "The influence of highspeed rail on ice-snow tourism in northeastern China," Tourism Management, vol. 78, Article ID 104070, 2020.

[55] B. Lin, "Population ageing in rural China: trends, impacts and suggestions," West Forum, vol. 25, no. 2, pp. 73-81, 2015.

[56] D. E. Bloom, S. Chatterji, P. Kowal et al., "Macroeconomic implications of population ageing and selected policy responses," The Lancet, vol. 385, no. 9968, pp. 649-657, 2015.

[57] R. N. Cooper and P. G. Peterson, "Gray dawn: how the coming age wave will transform America and the world," Foreign Affairs, vol. 78, no. 2, p. 142, 1999.

[58] S. Liu and S. M. Griffiths, "From economic development to public health improvement: China faces equity challenges," Public Health, vol. 125, no. 10, pp. 669-674, 2011. 